\title{
Antiadenoviral effects of ganciclovir in types inducing keratoconjunctivitis by quantitative polymerase chain reaction methods
}

This article was published in the following Dove Press journal:

Clinical Ophthalmology

30 January 2014

Number of times this article has been viewed

\author{
Jane Huang' \\ Kazuaki Kadonosono ${ }^{2}$ \\ Eiichi Uchio' \\ 'Department of Ophthalmology, \\ Fukuoka University School of \\ Medicine, Fukuoka, ${ }^{2}$ Department \\ of Ophthalmology, Yokohama City \\ University Medical Center, \\ Yokohama, Japan
}

Correspondence: Eiichi Uchio Department of Ophthalmology, Fukuoka University School of Medicine, 7-45-I Nanakuma, Jonan-ku, Fukuoka 8I4-0I80, Japan

Tel +8192801 I0I I

Fax +8I 928654445

Email euchio@fukuoka-u.ac.jp
Purpose: The most common external ocular viral infections are caused by several human adenovirus (HAdV) types. Ganciclovir has been reported to inhibit cytomegalovirus, herpes simplex virus types 1 and 2, varicella zoster virus, and Epstein-Barr virus. Ganciclovir ophthalmic gel, $0.15 \%$ (Virgan $\left.^{\circledR}\right)$ is commercially available for cytomegalovirus or herpes virus keratitis. However its inhibitory activity against HAdV is reported only for types 2 and 5. We investigated the antiadenoviral activity of ganciclovir in vitro in several common types currently inducing keratoconjunctivitis.

Materials and methods: A549 cells were used for viral cell culture, and adenovirus types 3 (HAdV3; species B), 4 (species E), and 8, 19a, and 37 (species D) were used. After pretreatment of A549 with serial dilutions of ganciclovir for 24 hours, adenovirus was cultured for 7 days, and adenoviral deoxyribonucleic acid was quantitatively measured by real-time polymerase chain reaction $(\mathrm{PCR})$.

Results: The $50 \%$ cytotoxic concentration of ganciclovir was $212 \mu \mathrm{g} / \mathrm{mL}$. The $50 \%$ effective concentration of ganciclovir obtained by real-time PCR ranged between 2.64 and $5.10 \mu \mathrm{g} / \mathrm{mL}$. A significant inhibitory effect of ganciclovir on adenoviral proliferation was found in all types in a dose-dependent manner. The selectivity index of ganciclovir ranged between 41.6 and 80.3. Conclusion: Ganciclovir showed significant inhibitory activity against HAdV3, 4, 8, 19a, and 37, which induce epidemic keratoconjunctivitis. These results indicate that ganciclovir is a possible candidate for the treatment of HAdV keratoconjunctivitis, and ganciclovir ophthalmic gel could be applied to adenoviral keratoconjunctivitis in the future.

Keywords: adenovirus, ganciclovir, epidemic keratoconjunctivitis, nucleoside analog, A549 cell line

\section{Introduction}

As a systemic infection, human adenovirus (HAdV) infects the respiratory tract, intestinal tract, and in rare cases the liver and kidneys, and has a variety of clinical manifestations. The HAdV family consists of 57 known types, which are currently increasing in number due to the recent introduction of a phylogenetic classification, which fall into seven species - A to G. ${ }^{1-4}$ Pediatric patients undergoing allogeneic stem cell transplantation are particularly prone to disseminated HAdV infections, with high associated morbidity and mortality. ${ }^{5}$ Severe systemic HAdV infection can also occur in patients with acquired immune deficiency syndrome. ${ }^{6}$ During the past decade, the growing practice of transplantation accompanied by strong immunosuppressive therapy has led to a gradual increase in the incidence of severe HAdV infections. Many HAdV types also cause the most common external ocular viral infections worldwide. 
In particular, adenoviral conjunctivitis is known to be the major cause of acute contagious infections associated with community and nosocomial epidemics. ${ }^{7,8}$ Thus, the development of effective antiadenoviral drugs for the clinical treatment of adenoviral conjunctivitis or systemic HAdV infectious diseases is important.

The treatment of adenoviral ocular infections is controversial, and at this time, there is no approved antiviral therapy for HAdV infections. There is an increasing need for new antiviral therapeutics with potent activity against HAdVs and a favorable therapeutic index. Case studies on the nucleoside analog ribavirin have yielded conflicting results. ${ }^{9-11}$ Recently, several investigators, including our group, reported that cidofovir, ${ }^{12,13}$ zalcitabine, ${ }^{14}$ and stavudine ${ }^{15}$ were effective in inhibiting HAdV replication. Cidofovir was also found to be beneficial in several small-scale studies involving patients with life-threatening HAdV infections., ${ }^{9,16}$ The treatment of ocular adenovirus infections is controversial, and there exists no approved antiviral treatment known to prevent or lessen the ocular sequelae of HAdV-induced diseases.

Ganciclovir is a synthetic nucleoside analog of $2^{\prime}$-deoxyguanosine. Its structure is 9-(1,3-dihydroxy2 -propoxymethyl) guanine. Ganciclovir has been reported to inhibit cytomegalovirus, herpes simplex virus types 1 and 2, varicella zoster virus, and Epstein-Barr virus. ${ }^{17}$ Commercially available outside the US since 1996 , ganciclovir ophthalmic gel $0.15 \%$ (Virgan ${ }^{\circledR}$; FarmilaThea, Milan, Italy) is sold in more than 30 countries and has become the standard of care in treating acute herpetic keratitis. ${ }^{18}$ As for HAdV, there are a restricted number of studies that have reported the antiviral activity of ganciclovir against $\mathrm{HAdV}{ }^{19-21}$

In the present study, using real-time polymerase chain reaction (PCR) to directly quantify HAdV progeny in virusinfected cells, we investigated whether ganciclovir displays potent and selective antiviral activity against HAdV types causing keratoconjunctivitis, 3, 4, 8, 19a, and 37.

\section{Materials and methods}

\section{Experimental compound and cells}

Ganciclovir (9-[\{1,3,-dihydroxy-2-propoxy $\}$ methyl] guanine) (Denosine ${ }^{\circledR}$; Mitsubishi Tanabe Pharma, Tokyo, Japan) was obtained from a commercial source. A549 cells (alveolar epithelial cells, CCL-185) were obtained from the American Type Culture Collection (ATCC, Manassas, VA, USA) and cultured in Eagle's Minimum Essential Medium (MEM; Nissui, Tokyo, Japan) containing $2 \mathrm{mM}$ L-glutamine, $0.1 \mathrm{mM}$ nonessential amino acids, and 7\% fetal calf serum.

\section{Viruses}

HAdV type 3 (HAdV3), HAdV4, HAdV8, HAdV19, and HAdV37 were used. HAdV3, 4, 8, and 37 were prototype strains, and were provided by the ATCC. Since HAdV19p (prototype strain) has never induced keratoconjunctivitis, ${ }^{22}$ we used a clinical strain, HAdV19a, for this study. These strains were propagated in $\mathrm{A} 549$ cells and stored at $-80^{\circ} \mathrm{C}$ until use.

\section{Cytotoxicity assay}

The cytotoxicity of ganciclovir was evaluated in A549 cells. This assay was carried out according to our previous report. ${ }^{15}$ In brief, dilutions of ganciclovir were prepared in Eagle's Minimum Essential Medium supplemented with 2\% fetal calf serum. The medium was then discarded and replaced for 24 hours by medium containing eight concentrations of ganciclovir: $62.5,125,250,500,1,000,2,000,4,000$, and $8,000 \mu \mathrm{g} / \mathrm{mL}$. After 7 days' incubation at $37^{\circ} \mathrm{C}$ with $5 \% \mathrm{CO}_{2}$, the cells in the plates were then subjected to a 3-(4,5-dimethylthiazol-2-yl)-5-(3-carboxymethoxyphenyl)2-(4-sulfophenyl)-2H-tetrazolium (MTS)-based colorimetric assay for cell viability according to the manufacturer's instructions (CellTiter $96^{\circledR}$ Aqueous One solution reagent; Promega Corporation, Fitchburg, WI, USA). A490 values, corrected for the cytotoxicity exerted by ganciclovir (as determined in mock-infected cultures), were used to calculate the percentage of cell viability. The $50 \%$ cytotoxic concentration $\left(\mathrm{CC}_{50}\right)$ was determined as the value causing destruction of $50 \%$ of the monolayer cells, by regression analysis.

\section{Antiviral experiments in A549 cells using real-time PCR}

The following virus-culture step was carried out as per our previous work. ${ }^{15}$ First, A549 cells were seeded in wells of 96-well plates at 10,000 cells per well and incubated for 4 or 5 days until confluence was reached. Then, $50 \mu \mathrm{L} \mathrm{HAdV}$, diluted in medium to obtain a virus input of five plaqueforming units per well, was added to each well. After 2 hours at $37^{\circ} \mathrm{C}$, the virus suspension was aspirated and replaced by serial dilutions of the ganciclovir compound $(200 \mu \mathrm{L}$ per well). The concentration of ganciclovir was determined for several dilutions of the $\mathrm{CC}_{50}$ of ganciclovir. Mock-treated cultures receiving only ganciclovir were included in each plate. After 7 days of incubation at $37^{\circ} \mathrm{C}$, microscopy was performed to score the virus-induced cytopathic effect. After removal of the culture supernatant, cells and virus particles were lysed by the addition of $70 \mu \mathrm{L}$ lysis buffer $(10 \mathrm{mM}$ Tris- $\mathrm{HCl}$ [pH 7.8], 0.5\% sodium dodecyl sulfate, $5 \mathrm{mM}$ 
$\mathrm{Na}_{2}$ ethylenediaminetetraacetic acid, and $80 \mu \mathrm{g}$ proteinase $\mathrm{K} / \mathrm{mL}$ ) and incubated at $50^{\circ} \mathrm{C}$ for 1 hour and then at $65^{\circ} \mathrm{C}$ for 20 minutes to inactivate the proteinase $\mathrm{K}$. After centrifugation $(23,000 \times g, 10$ minutes $)$, soluble cell extracts were stored at $-20^{\circ} \mathrm{C}$ until real-time PCR was performed. The following real-time PCR assay was conducted according to a previous study by Miura-Ochiai et al. ${ }^{23}$ Extracts were diluted 100-fold in water. Then, $2 \mu \mathrm{L}$ diluted extract was added to each well in optical plates containing $23 \mu \mathrm{L}$ SYBR green ${ }^{24}$ PCR master mix (Life Technologies, Carlsbad, CA, USA), and forward and reverse primers $(300 \mu \mathrm{M})$ were added to the wells. The primers, derived from GenBank sequences, were chosen to amplify a $137 \mathrm{bp}$ fragment in the conserved HAdV hexon deoxyribonucleic acid (DNA) sequence, allowing analysis of all known HAdV types (forward primer, 5'-CGCTGGACATGACTTTTGAG-3'; reverse primer, 5'-GAACGGTGTGCGCAGGTA-3'). Real-time PCR analysis was performed in an ABI Prism 7000 apparatus (Life Technologies) and consisted of 10 -minute activation at $95^{\circ} \mathrm{C}$, followed by 40 thermal cycles, each consisting of 15 seconds at $95^{\circ} \mathrm{C}$ and 90 seconds at $60^{\circ} \mathrm{C}$. The therapeutic index of a drug is the ratio of the dose that results in an undesired effect to that which results in a desired effect. It is usually defined as the ratio of half-maximal inhibitory concentration to $50 \%$ effective concentration $\left(\mathrm{EC}_{50}\right)$, which indicates how selective the drug is in eliciting its desired effect. $\mathrm{EC}_{50}$ was calculated from the dose response to ganciclovir measured 7 days postinfection, and corresponded to the ganciclovir concentration reducing the number of viral DNA copies by $50 \%$. In this study, for this purpose, the selectivity index $\left(\mathrm{CC}_{50} / \mathrm{EC}_{50}\right)$ of ganciclovir for each HAdV type was calculated based on the ratio of $\mathrm{CC}_{50}$ and $\mathrm{EC}_{50}$. Experiments were carried out in triplicate for each type.

\section{Statistics}

Nonparametric analysis was conducted. The ShirleyWilliams' multiple comparison test (nonparametricalized Williams' test) was used to detect the significance of the dosedependence of the tested agent in each serotype. A level of $P<0.05$ was accepted as statistically significant.

\section{Ethical consideration}

This research adhered to the tenets of the Declaration of Helsinki.

\section{Results \\ Cytotoxicity of tested compound}

The $\mathrm{CC}_{50}$ of ganciclovir was $212 \mu \mathrm{g} / \mathrm{mL}(827 \mu \mathrm{M})$ (Figure 1). Based on this value, an experiment on its inhibitory effect on HAdV proliferation was carried out at four concentrations: 10-, 20-, 40- and 80-fold dilutions (20, 10, 5 , and $2.5 \mu \mathrm{g} / \mathrm{mL}$ ) of $\mathrm{CC}_{50}$.

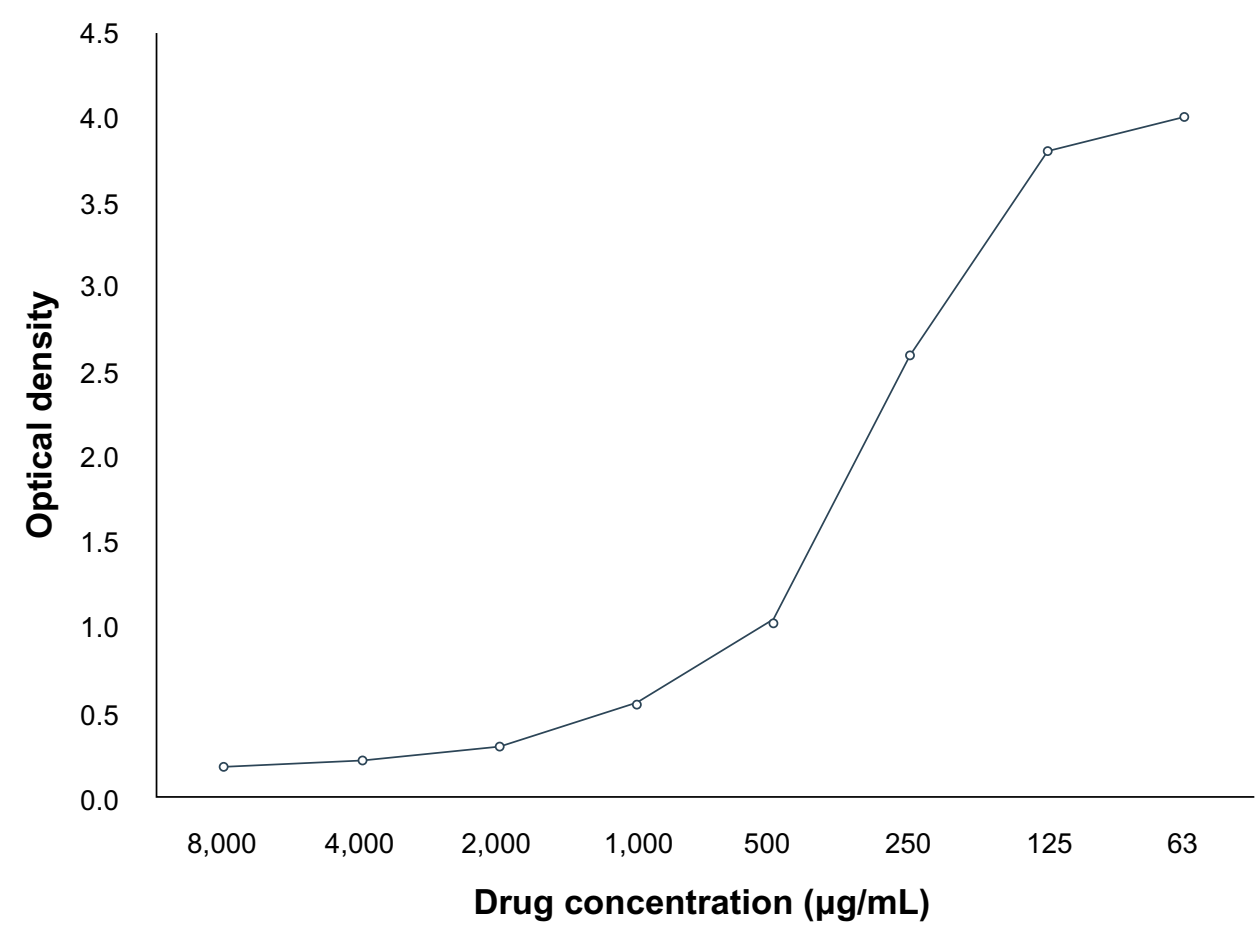

Figure I Results of toxicity assay of ganciclovir in the A549 cell line. According to the dose and cell viability from this graph, the $50 \%$ cytotoxic concentration of ganciclovir was calculated as $212 \mu \mathrm{g} / \mathrm{mL}$. 


\section{Quantitative analysis of antiadenoviral effect and selectivity index}

The relationship between the concentration of ganciclovir and decrease in virus copy number is shown in Table 1 . Ganciclovir showed a dose-dependent inhibitory effect on all types. The $\mathrm{EC}_{50}$ of ganciclovir ranged between 2.64 and $5.10 \mu \mathrm{g} / \mathrm{mL}$ (10.3 and $19.9 \mu \mathrm{M})$ (Table 1). The selectivity index of ganciclovir ranged between 41.6 and 80.3. A significant inhibitory effect of ganciclovir against HAdV was observed in all types at various concentrations compared with controls (Table 1).

\section{Discussion}

In this study, ganciclovir had a significant inhibitory effect in a dose-dependent manner against all selected types of HAdV - HAdV3, 4, 8, 19a, and 37 - which induce epidemic keratoconjunctivitis. Ganciclovir is reported to be effective against HAdV $2^{19,20}$ and HAdV $5^{21}$ in vitro and in vivo. However, these types rarely induce keratoconjunctivitis in Southeast Asia, especially in Japan. ${ }^{25}$ Epidemic keratoconjunctivitis (EKC) is mainly caused by species $\mathrm{D}$ adenoviruses of types 8 , 19 , and $37 .{ }^{25}$ Types 3,4 , and 7 , which belong to species B, also cause conjunctivitis and pharyngoconjunctival fever. ${ }^{26}$ The susceptibility of HAdV to antiviral drugs is not comparable but is species-dependent. ${ }^{27}$ The antiviral activity of ganciclovir against HAdV has been reported in an animal model, but this model lacked clinical signs of keratoconjunctivitis. ${ }^{22}$ Therefore, it is currently necessary to include various types of HAdV to evaluate the antiviral effect of chemical compounds in in vitro-based study. We selected HAdV types 3, 4, 8, 19a, and 37 in this study, not only to evaluate the antiadenoviral activity of ganciclovir but also to survey its possible use as eyedrops in the field of clinical ophthalmology. Kaneko et al reported that they identified novel HAdV53 and HAdV54 from a recent epidemic of keratoconjunctivitis in Japan. ${ }^{25}$ Thus, it seems worthwhile to analyze these new types in our study. However, we have previously carried out a series of studies evaluating the antiadenoviral activity of several agents, such as stavudine, ${ }^{15} \mathrm{~N}$-chlorotaurine, ${ }^{28}$ and the a5b1 integrin-receptor ligand GRGDSP peptide, ${ }^{29}$ using almost the same protocol. Thus, we selected the same five adenovirus types in this study. Among adenovirus types, the inhibitory activity (50\% effective dose) of ganciclovir for those types inducing keratoconjunctivitis - HAdV4, HAdV8, and HAdV19 - was 8.1, 15.0 and $7.2 \mu \mathrm{M}$, respectively, in the middle of the range of other types. ${ }^{18}$ This suggests the possible usefulness of ganciclovir against adenoviral disorders, including keratoconjunctivitis. Our study was then carried out to include more types to monitor the antiadenoviral effect of ganciclovir, and its safety was also investigated. We used $\mathrm{EC}_{50}$ in our study. $\mathrm{EC}^{50}$ values in our study were similar to the results reported by Colin. ${ }^{18}$

Several nucleoside or nucleotide analogs are currently being used clinically for adenovirus infection in immunocompromised hosts. Both ribavirin and cidofovir exhibit inhibitory activity in vitro against HAdV. ${ }^{13,21}$ Several antiadenoviral agents are associated with significant side effects. Nephrotoxicity is the major risk in patients receiving cidofovir, whereas extravascular hemolysis, anemia, and bone marrow suppression are the most common dose-limiting toxic side effects of ribavirin..$^{30,31}$ Local toxicity of cidofovir in the skin of the eyelids and conjunctiva is reported in patients with adenoviral keratoconjunctivitis. ${ }^{32}$ Therefore, there is an important need for selective antiadenoviral drugs with more favorable safety profiles than those of the currently available nucleoside and nucleotide analogs. A possible benefit of ganciclovir has been suggested by Bruno et al, who found the incidence of HAdV infections in stem cell-transplant recipients to be somewhat reduced in those receiving ganciclovir for human cytomegalovirus prophylaxis..$^{33}$

In several reports, the effectiveness of systemic administration of ganciclovir has been reported. ${ }^{34-36}$ As for local use,

Table I Antiviral activity of ganciclovir against human adenovirus (HAdV) types 3, 4, 8, 19a, and 37, and selectivity index

\begin{tabular}{|c|c|c|c|c|c|}
\hline \multirow{2}{*}{$\begin{array}{l}\text { Ganciclovir } \\
\text { concentration }(\mu \mathrm{g} / \mathrm{mL})\end{array}$} & \multicolumn{5}{|c|}{ Number of AdV copies (log copies/mL; means \pm SEM) } \\
\hline & HAdV type 3 (HAdV3) & HAdV4 & HAdV8 & HAdVI9a & HAdV37 \\
\hline Control & $1 \mathrm{I} .33 \pm 0.07$ & $11.00 \pm 0.22$ & $9.58 \pm 0.14$ & $1 \mathrm{I} .77 \pm 0.04$ & $|I .5| \pm 0.09$ \\
\hline 2.5 & $11.20 \pm 0.02$ & $10.88 \pm 0.02$ & $9.52 \pm 0.02$ & $11.65 \pm 0.15$ & $11.30 \pm 0.32$ \\
\hline 5 & $11.03 \pm 0.06 *$ & $10.68 \pm 0.09$ & $9.13 \pm 0.76$ & $11.21 \pm 0.07^{*}$ & $10.90 \pm 0.10^{*}$ \\
\hline 10 & $10.83 \pm 0.06 *$ & $10.39 \pm 0.09 *$ & $8.58 \pm 0.77$ & $10.98 \pm 0.06 *$ & $10.69 \pm 0.55 *$ \\
\hline 20 & $10.36 \pm 0.16 *$ & $10.18 \pm 0.20 *$ & $8.35 \pm 0.94 *$ & $10.87 \pm 0.47^{*}$ & $10.32 \pm 0.67 *$ \\
\hline $\mathrm{EC}_{50}(\mu \mathrm{g} / \mathrm{mL})$ & $5.10(19.9 \mu \mathrm{M})$ & $4.82(18.9 \mu \mathrm{M})$ & $3.93(\mathrm{I} 5.4 \mu \mathrm{M})$ & $2.94(\mathrm{II} .5 \mu \mathrm{M})$ & $2.64(10.3 \mu \mathrm{M})$ \\
\hline Selectivity index & 41.6 & 44.0 & 53.9 & 72.1 & 80.3 \\
\hline
\end{tabular}

Note: *Statistically significant dose-dependent inhibitory effect compared with control $(P<0.05)$.

Abbreviations: SEM, standard error of mean; $\mathrm{EC}_{50}, 50 \%$ effective concentration. 
it was reported that ganciclovir ophthalmic gel $0.15 \%$ can be effective not only for herpes simplex virus but also for adenoviral keratoconjunctivitis ${ }^{18,37}$; however, its antiadenoviral activity in vivo was not described. Compared with other antiviral agents, the $\mathrm{EC}_{50}$ of zalcitabine and stavudine for HAdV8 was 0.55 and $4.52 \mu \mathrm{M}$, respectively, ${ }^{15}$ and that of ganciclovir was $15.4 \mu \mathrm{M}$ in our present study. It seems that this value is larger, meaning less specificity, than that of the anti-human immunodeficiency virus agents; however, the antiadenoviral effect of ganciclovir is in the acceptable range for clinical use. Unfortunately, commercially available ganciclovir ophthalmic gel $0.15 \%$ (Virgan) is not authorized for use in Japan, as in the US, even for cytomegalovirus keratitis. However, considering the notable and wide-ranging inhibitory effect of ganciclovir against adenovirus from the results of this study, local use of ganciclovir ophthalmic gel for adenoviral keratoconjunctivitis is the most favorable candidate for future treatment of this disease, which causes considerable epidemics worldwide, including Southeast Asia. Although we have not established a reliable animal model with clinical symptoms of adenoviral keratoconjunctivitis, further investigation by animal experiments and human clinical trials is needed.

\section{Acknowledgments}

This work was supported by a Grant-in-Aid for Encouragement of Scientists (21592269) from the Ministry of Education, Science, Sports and Culture of Japan. We thank Dr W Gray for editing this manuscript.

\section{Disclosure}

The authors report no conflicts of interest in this work.

\section{References}

1. De Jong JC, Wermenbol AG, Verweij-Uijterwaal MW, et al. Adenoviruses from human immunodeficiency virus-infected individuals, including two strains that represent new candidate serotypes Ad50 and Ad51 of species B1 and D, respectively. J Clin Microbiol. 1999;37(12):3940-3945.

2. Wadell G, Hammarskjold ML, Winberg G, Varsanyi TM, Sundell G. Genetic variability of adenoviruses. Ann N Y Acad Sci. 1980;354(1): $16-42$.

3. Walsh MP, Seto J, Jones MS, Chodosh J, Xu W, Seto D. Computational analysis identifies human adenovirus type 55 as a re-emergent acute respiratory disease pathogen. J Clin Microbiol. 2010;48(3):991-993.

4. Kaneko H, Aoki K, Ohno S, et al. Complete genome analysis of a novel intertypic recombinant human adenovirus causing epidemic keratoconjunctivitis in Japan. J Clin Microbiol. 2011;49(2):484-490.

5. Walls T, Shankar AG, Shingadia D. Adenovirus: an increasingly important pathogen in paediatric bone marrow transplant patients. Lancet Infect Dis. 2003;3(2):79-86.

6. Zarraga AL, Kerns FT, Kitchen LW. Adenovirus pneumonia with severe sequelae in an immunocompetent adult. Clin Infect Dis. 1992;15(4): $712-713$.
7. Ford E, Nelson KE, Warren E. Epidemiology of epidemic keratoconjunctivitis. Epidemiol Rev. 1987;9(2):244-261.

8. Jernigan JA, Lowry BS, Hayden FG, et al. Adenovirus type 8 epidemic keratoconjunctivitis in an eye clinic: risk factors and control. $J$ Infect Dis. 1993;167(6):1307-1313.

9. Bordigoni P, Carret AS, Venard V, Witz F, Le Faou A. Treatment of adenovirus infections in patients undergoing allogeneic hematopoietic stem cell transplantation. Clin Infect Dis. 2001;32(9):1290-1297.

10. Gavin PJ. Katz BZ. Intravenous ribavirin treatment for severe adenovirus disease in immunocompromised children. Pediatrics. 2002; 110(1 Pt 1):1-8.

11. Lankester AC, Heemskerk B, Claas EC, et al. Effect of ribavirin on the plasma viral DNA load in patients with disseminating adenovirus infection. Clin Infect Dis. 2004;38(11):1521-1525.

12. de Oliveira B, Stevenson D, LaBree L, McDonnel PJ, Trousdale MD. Evaluation of cidofovir (HPMPC, GS-504) against adenovirus type 5 infection in vitro and in a New Zealand rabbit ocular model. Antiviral Res. 1996;31(3):165-172.

13. Gordon YG, Romanowski EG, Araullo-Cruz TP, et al. Inhibitory effect of (S)-HPMPC, (S)-HPMPA, and 2'-nor-cyclic-GMP on clinical ocular adenoviral isolates is serotype-dependent in vitro. Antiviral Res. 1991;16(1):11-16.

14. Mentel R, Kinder M, Wegner U, Janta-Lipinski M, Matthes E. Inhibitory activity of 3 '-fluoro- 2 '-deoxythymidine and related nucleoside analogues against adenovirus in vitro. Antiviral Res. 1997;34(3):113-119.

15. Uchio E, Fuchigami A, Kadonosono K, et al. Anti-adenoviral effect of anti-HIV agents in vitro in serotypes inducing keratoconjunctivitis. Graefes Arch Clin Exp Ophthalmol. 2007;245(9):1319-1325.

16. Hoffman JA, Shah AJ, Ross LA, Kapoor N. Adenoviral infections and a prospective trial of cidofovir in pediatric hematopoietic stem cell transplantation. Biol Blood Marrow Transplant. 2001;7(7): 388-394.

17. Trousdale MD, Nesburn AB, Willey DE, Taaid H. Efficacy of BW759 (9-[[2-hydroxy-1-(hydroxymethyl)ethoxy]methyl]guanine) against herpes simplex virus type 1 keratitis in rabbits. Curr Eye Res. 1984;3(8):1007-1015.

18. Colin J. Ganciclovir ophthalmic gel, $0.15 \%$ : a valuable tool for treating ocular herpes. Clin Ophthalmol. 2007:1(4):441-453.

19. Smith KO, Galloway KS, Kennell WL, Ogilvie KK, Radatus BK. A new nucleoside analog, 9-[[2-hydroxy-1(hydroxymethyl)ethoxy]methyl] guanine, highly active in vitro against herpes simplex virus types 1 and 2. Antimicrob Agents Chemother. 1982;22(1):55-61.

20. Naesens L, Lenaerts L, Andrei G, et al. Antiadenovirus activities of several classes of nucleoside and nucleotide analogues. Antimicrob Agents Chemother. 2005;49(3):1010-1016.

21. Trousdale MD, Goldschmidt PL, Nóbrega R. Activity of ganciclovir against human adenovirus type- 5 infection in cell culture and cotton rat eyes. Cornea. 1994;13(5):435-439.

22. Noda M, Otagaki Y, Ikeda Y, Matsuishi T, Ogino T. Genome types of adenovirus types 19 and 37 isolated from patients with conjunctivitis in Hiroshima City. J Med Virol. 1988;26(1):15-22.

23. Miura-Ochiai R, Shimada Y, Konno T, et al. Quantitative detection and rapid identification of human adenoviruses. J Clin Microbiol. 2007;45(3):958-967.

24. Zipper H, Brunner H, Bernhagen J, Vitzthum F. Investigations on DNA intercalation and surface binding by SYBR Green I, its structure determination and methodological implications. Nucleic Acids Res. 2004:32(12):e103.

25. Kaneko H, Suzutani T, Aoki K, et al. Epidemiological and virological features of epidemic keratoconjunctivitis due to new human adenovirus type 54 in Japan. Br J Ophthalmol. 2011;95(1):32-36.

26. O'Donnell B, McCruden EA, Desselberger U. Molecular epidemiology of adenovirus conjunctivitis in Glasgow 1981-1991. Eye (Lond). 1993;7(Pt 3 Suppl):8-14.

27. Morfin F, Dupuis-Girod S, Mundweiler S, et al. In vitro susceptibility of adenovirus to antiviral drugs is species-dependent. Antivir Ther. 2005;10(2):225-229. 
28. Uchio $\mathrm{E}$, Inoue $\mathrm{H}$, Kadonosono $\mathrm{K}$. Antiadenoviral effects of $\mathrm{N}$-chlorotaurine in vitro confirmed by quantitative polymerase chain reaction methods. Clin Ophthalmol. 2010;19(4):1325-1329.

29. Uchio E, Kimura R, Huang YH, et al. Anti-adenoviral effect of a5b1 integrin receptor ligand, GRGDSP peptide, in serotypes that cause acute keratoconjunctivitis. Ophthalmologica. 2007;221(5):326-330.

30. Fanourgiakis P, Georgala A, Vekemans M, et al. Intravesical instillation of cidofovir in the treatment of hemorrhagic cystitis caused by adenovirus type 11 in a bone marrow transplant recipient. Clin Infect Dis. 2005;40(1):199-201.

31. Ljungman P. Treatment of adenovirus infections in the immunocompromised host. Eur J Clin Microbiol Infect Dis. 2004;23(8):583-588.

32. Hillenkamp J, Reinhard T, Ross RS, et al. The effects of cidofovir $1 \%$ with and without cyclosporin A $1 \%$ as a topical treatment of acute adenoviral keratoconjunctivitis: a controlled clinical pilot study. Ophthalmology. 2002;109(5):845-850.
33. Bruno B, Gooley T, Hackman RC, Davis C, Corey L, Boeckh M. Adenovirus infection in hematopoietic stem cell transplantation: effect of ganciclovir and impact on survival. Biol Blood Marrow Transplant. 2003;9(5):341-352.

34. Wreghitt TG, Gray JJ, Ward KN, et al. Disseminated adenovirus infection after liver transplantation and its possible treatment with ganciclovir. J Infect. 1989;19(1):88-89.

35. Duggan JM, Farrehi J, Duderstadt S, Turner NJ, Fekety R. Treatment with ganciclovir of adenovirus pneumonia in a cardiac transplant patient. Am J Med. 1997;103(5):439-440.

36. Chen FE, Liang RH, Lo JY, Yuen KY, Chan TK, Peiris M. Treatment of adenovirus-associated haemorrhagic cystitis with ganciclovir. Bone Marrow Transplant. 1997;20(11):997-999.

37. Kaufman HE, Haw WH. Ganciclovir ophthalmic gel $0.15 \%$ : safety and efficacy of a new treatment for herpes simplex keratitis. Curr Eye Res. 2012;37(7):654-660.
Clinical Ophthalmology

\section{Publish your work in this journal}

Clinical Ophthalmology is an international, peer-reviewed journal covering all subspecialties within ophthalmology. Key topics include: Optometry; Visual science; Pharmacology and drug therapy in eye diseases; Basic Sciences; Primary and Secondary eye care; Patient Safety and Quality of Care Improvements. This journal is indexed on

\section{Dovepress}

PubMed Central and CAS, and is the official journal of The Society of Clinical Ophthalmology (SCO). The manuscript management system is completely online and includes a very quick and fair peer-review system, which is all easy to use. Visit http://www.dovepress.com/ testimonials.php to read real quotes from published authors. 